\title{
Alternance électrique lors d'un pneumothorax spontané
}

\section{Electrical alternans in spontaneous pneumothorax}

\section{A. Verrat $\cdot$ O. Peyrony $\cdot$ P. Taboulet}

Reçu le 23 août 2013 ; accepté le 28 octobre 2013

(C) SFMU et Springer-Verlag France 2013

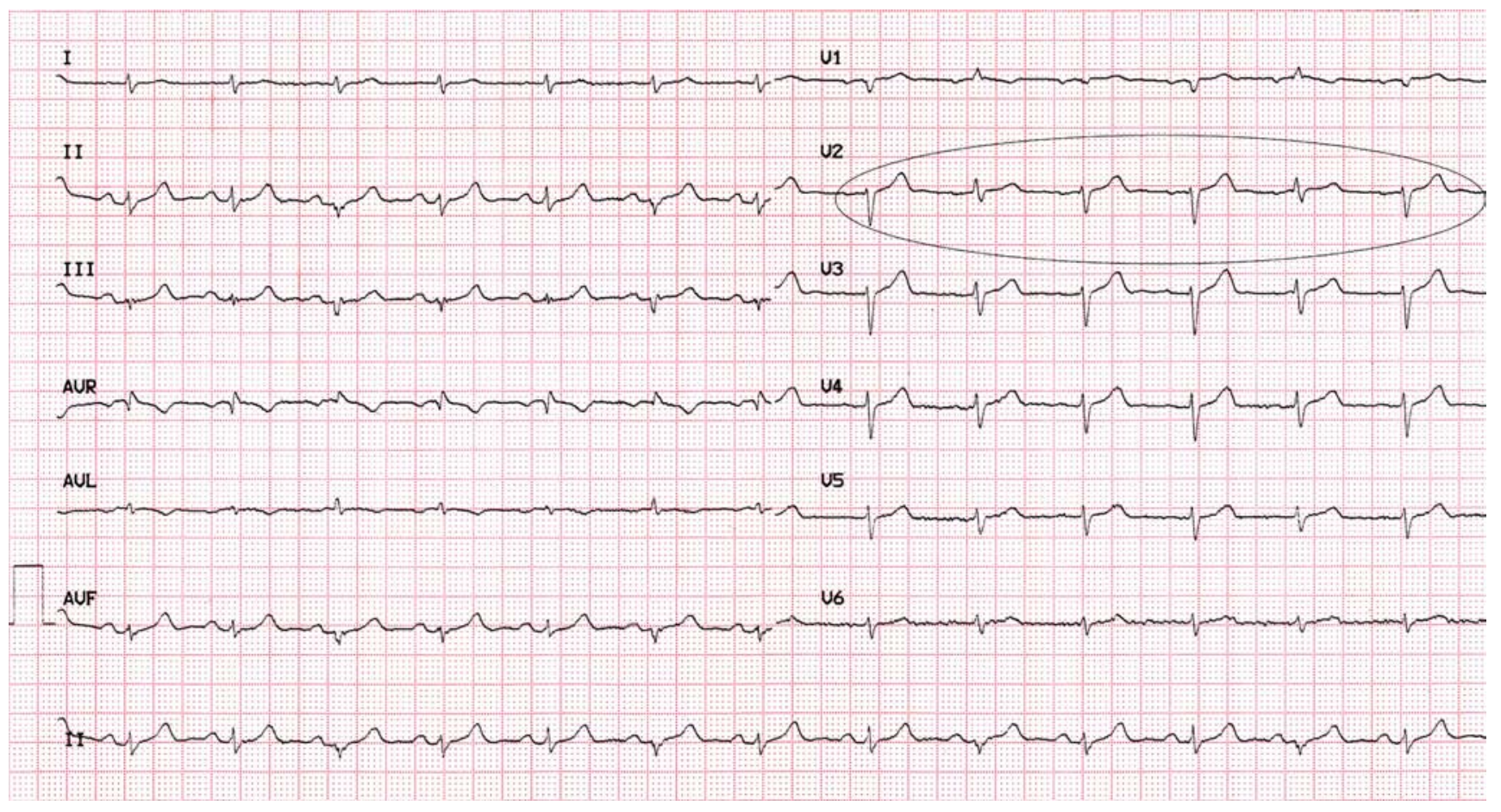

Fig. 1 ECG d'épanchement péricardique abondant avec microvoltage et alternance électrique

Un homme de 63 ans, consulte aux urgences pour une douleur thoracique gauche évoluant depuis $48 \mathrm{~h}$. L'examen ne montre pas de signe de choc ou de détresse respiratoire. L'auscultation révèle une diminution du murmure vésiculaire de l'hémichamp pulmonaire gauche. L'ECG montre une tachycardie sinusale avec une alternance électrique totale (P-QRS-T) $3: 1$ suivant les mouvements respiratoires et un micorvoltage diffus (Fig. 1). Les causes d'alternance électrique sont un épanchement péricardique (swinging heart), un pneumothorax, un épanchement pleural ou une anomalie intermittente de la conduction lors de certains troubles du rythme (tachycardie orthodromique avec conduction variable sur faisceau accessoire, aberration au cours des tachycardies supraventriculaires, torsades de pointes, tachycardie ventriculaire bidirectionnelle...). La radiographie de thorax révèle un pneumothorax gauche complet compressif.

A. Verrat $(\varangle) \cdot$ O. Peyrony $\cdot$ P. Taboulet

Hôpital Saint-Louis, Assistance publique-hôpitaux de Paris,

service des urgences, 1, avenue Claude Vellefaux,

F-75010, Paris, France

e-mail : anne.verrat@gmail.com 